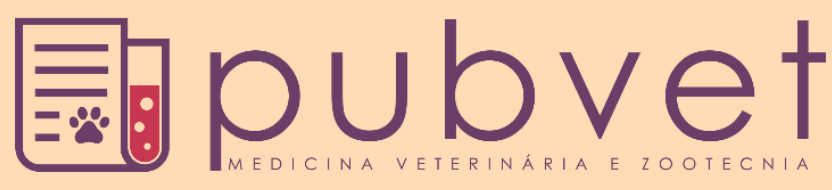

https://doi.org/10.31533/pubvet.v15n04a800.1-5

\title{
Programa de aquisição de alimentos no município de Bacuri, Maranhão
}

Tielle da Luz Tavares ${ }^{1 *}$, Sarah Semene Rocha Garcia ${ }^{2}$, Claudenilde de Jesus Pinheiro Costa ${ }^{3}$, Sánara Adrielle França Melo ${ }^{4} \bullet$, Gleice Kelle Silva Marques Vilela ${ }^{\circ}$, Gabriela Duarte Silva ${ }^{3}{ }^{\circ}$,

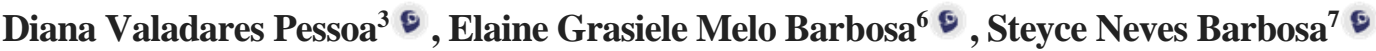

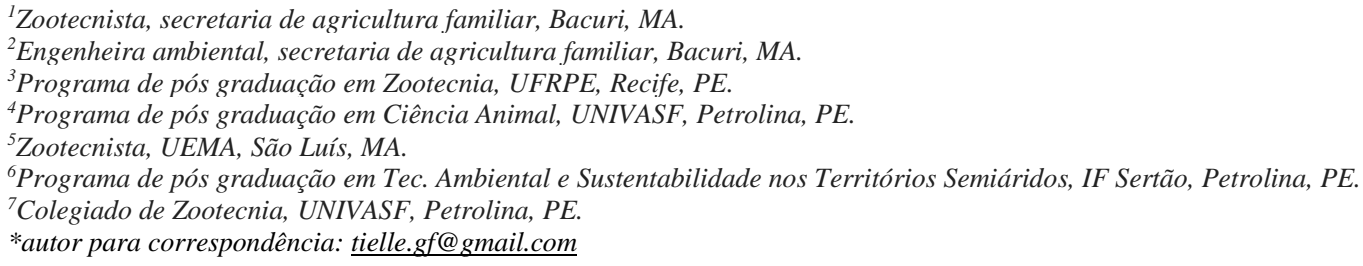

Resumo. O programa de aquisição de alimentos forma estoque e fornece às entidades beneficiadas os alimentos produzidos pelos agricultores familiares. Objetivou-se levantar dados a respeito do Programa de Aquisição de Alimentos no município de Bacuri, Maranhão, Brasil. O Programa de Aquisição de Alimentos visa principalmente incentivar a agricultura familiar. Os dados do trabalho são da secretaria municipal de agricultura familiar e meio ambiente de Bacuri, MA. O programa conta com 35 agricultores familiares, com cinco entidades beneficiadas, conta com uma variedade de produtos comercializados, cuja predominância é a farinha. A própria secretária é a responsável por fazer a distribuição e prévia identificação de beneficiários dos produtos. O programa tem contribuído para o desenvolvimento do município, entidades beneficiadas e agricultores bacurienses.

Palavras-chave: agricultura familiar, entidades beneficiadas, políticas públicas

\section{Food acquisition program in the municipality of Bacuri, Maranhão}

\begin{abstract}
The food acquisition program forms stock and supplies the beneficiaries with food produced by family farmers. The objective was to collect data about the Food Acquisition Program in the municipality of Bacuri, Maranhão, Brazil. the Food Acquisition Program is mainly aimed at encouraging family farming. The data of the work are from the municipal secretary of family agriculture and environment of Bacuri, MA. The program has 35 family farmers, with five benefited entities, and has a variety of commercialized products, the predominance of which is flour. The secretary herself is responsible for making the distribution and prior identification of product beneficiaries. The program has contributed to the development of the municipality, benefited entities and bacurienses farmers.
\end{abstract}

Keywords: benefited entities, family farming, public policies

\section{Programa de adquisición de alimentos en el municipio de Bacuri, Maranhão}

Resumen. El programa de adquisición de alimentos forma existencias y proporciona a los beneficiarios alimentos producidos por agricultores familiares. El objetivo fue recolectar datos sobre el Programa de Adquisición de Alimentos en el municipio de Bacuri, Maranhão, Brasil. El Programa de Adquisición de Alimentos tiene como principal objetivo 
fomentar la agricultura familiar. Los datos del trabajo son de la Secretaría Municipal de Agricultura Familiar y Medio Ambiente de Bacuri, MA. El programa cuenta con 35 agricultores familiares, con cinco entidades beneficiadas, y cuenta con una variedad de productos comercializados, cuyo predominio es la harina. La propia secretaria se encarga de realizar la distribución e identificación previa de los productos beneficiarios. El programa ha contribuido al desarrollo del municipio, benefició a entidades y agricultores bacurienses.

Palabras clave: agricultura familiar, entidades beneficiadas, políticas públicas

\section{Introdução}

O Programa de Aquisição de Alimentos (PAA) surgiu em 2003 com o programa Fome Zero, lançado em outubro de 2001 pelo Instituto de Cidadania. O Conselho Nacional de Segurança Alimentar (CONSEA) foi quem orientou as tomadas de decisões quanto às diretrizes do programa no início do Governo Lula. O programa é também resultado de mobilizações sociais e demandas por maior acesso dos produtores as ações públicas (Camargo et al., 2013).

O PAA foi oficialmente instituído pela Lei no. 10.696, artigo 19 em 2006: fica instituído o Programa de Aquisição de Alimentos com a finalidade de incentivar a agricultura familiar, compreendendo ações vinculadas à distribuição de produtos agropecuários para pessoas à situação de insegurança alimentar e à formação de estoques estratégicos (Brasil, 2006). O programa age em dois aspectos importantes no suprimento alimentar da população: no momento produtivo e no momento do consumo (Chmielewska et al., 2010), realizando a compra dos alimentos produzidos pelos agricultores familiares, forma estoque e fornece as entidades beneficiadas combatendo a fome (Veloso, 2017).

O PAA também contribui para a constituição de estoques públicos de alimentos produzidos pelos agricultores familiares. Além disso, o programa promove o abastecimento alimentar por meio de compras governamentais de alimentos; fortalece circuitos locais e regionais e redes de comercialização; valoriza a biodiversidade e a produção orgânica e agroecológica de alimentos; incentiva hábitos alimentares saudáveis e estimula o cooperativismo e o associativismo (Brasil, 2010). O PAA sofreu alterações como: extinção de modalidade, maior fiscalização e controle social, mudanças nas normativas, valorização de produtos agroecológicos, exigência de percentual mínimo de mulheres, mas, nada que afetasse o compromisso assumido no ano de 2003, pelos diversos atores sociais e o fórum de comunidade de política pública (Grisa, 2012).

De acordo com Siliprandi \& Cintrão, (2011) podem participar do PAA homens e mulheres da agricultura, pesca artesanal, silvicultura, extrativistas, indígenas, membros de comunidades remanescentes de quilombos e agricultores assentados. As autoras ainda acrescentam que embora nos cadastros incluam dois titulares (o marido e a mulher), os pagamentos do fornecimento ao PAA (e os contratos) são feitos em nome de uma só pessoa, identificada por seu CPF.

De acordo com o IBGE, o município de Bacuri localizado no estado do maranhão, possui uma população estimada em 18.582 habitantes (IBGE, 2019) podendo ser encontradas várias famílias que vivem da agricultura e pecuária, que estão na atividade não apenas para subsistência, mas também para comercialização.

Vista a importância que o Programa de Aquisição de Alimentos (PAA) tem para o Brasil, sobretudo para o Nordeste, onde está inserido o estado do Maranhão e principalmente pequenos municípios como Bacuri, tanto para o público que recebe os produtos, bem como para a renda dos produtores, este trabalho objetivou levantar dados a respeito do programa no município de Bacuri, Maranhão, Brasil.

\section{Material e métodos}

Os dados foram provenientes da secretaria municipal de agricultura familiar e meio ambiente de Bacuri, MA. Onde se obteve dados referentes aos meses de janeiro a agosto de 2019, sobre entidades beneficiadas, quantidade de agricultores cadastrados no programa, descrição dos alimentos produzidos e seus respectivos valores. Realizou-se visitas para acompanhar como é feito a distribuição dos produtos, conhecer a área, bem como os produtores e entidades 


\section{Resultados e discussão}

O PAA no município de Bacuri, MA, recebe recurso do estado, mas é o município quem dá todo o suporte técnico para o funcionamento do programa. O programa no município conta com 35 agricultores familiares (Tabela 1), com predominância do sexo feminino. Segundo Siliprandi e Cintrão (2011), um conjunto de fatores interferem no percentual de mulheres participantes do PAA, podendo ter distintos significados. No caso de Bacuri, MA, há uma preferência para cadastro de mulheres, pois como o município concorre com outros municípios, ter maior percentual de mulheres no programa, faz com que pontuem mais nos projetos. Os produtores são selecionados por meio de editais anuais.

Os produtores atendem com o programa cinco entidades (Tabela 1). Das entidades tem-se três escolas, um hospital e um Centro de Referência da Assistência Social (CRAS). O público atendido é composto de alunos, pacientes e famílias carentes do município. O que no caso dos atendidos pelo CRAS contribui para manutenção das famílias em que o representante familiar ficou desempregado, por exemplo. Caso semelhante foi relatado em Tupi Paulista no estado de São Paulo, quanto à importância do PAA principalmente no momento em que os chefes da família, ficaram desempregados, os alimentos recebidos contribuíram na garantia da alimentação diária (Veloso, 2017). O PAA tem facilitado o acesso aos alimentos e a consequente diversificação e enriquecimento da alimentação servida nas escolas, creches, albergues, instituições de caridade e demais destinatárias dos alimentos adquiridos (Delgado, 2005).

Tabela 1. Participantes do PAA ${ }^{1}$ no município de Bacuri, Maranhão

\begin{tabular}{lc}
\hline Categoria & Total \\
\hline Agricultor familiar & 35 \\
Quilombola & 10 \\
Indígena & 1 \\
Assentado da reforma agrária & 2 \\
Assentado do ITERMA ${ }^{2}$ & 8 \\
Extrativistas & 20 \\
\hline
\end{tabular}

${ }^{1}$ Programa de Aquisição de Alimentos; ${ }^{2}$ instituto de colonização e terras do Maranhão.

O PAA proporciona o acesso aos alimentos (Quadro 1), como frutas, legumes e verduras, bolos, biscoitos, carnes, peixes e farinha. Esta última é o alimento predominante devido ao município ser referência nesta produção (Tabela 2). A entrega realizada do PAA SAF 2019 em farinha foi de 4.143,31 $\mathrm{kg}$, totalizando $\mathrm{R} \$ 21.338,04$. Já em 2018 , foi de $33.993,24 \mathrm{~kg}$, que totalizou $\mathrm{R} \$ 20.565,18$. Até o ano passado não tinha uma quantidade definitiva de farinha que podia ser entregue, por isso essa diferença de 2018 para 2019. Quanto aos alimentos entregues, a farinha, bolos e biscoitos podem ser entregues sem o SIF (selo de inspeção federal), devido ao seu processamento.

Quadro 1. Alimentos comercializados no Programa de Aquisição de Alimentos no munícipio de Bacuri, MA.

Abacate, abacaxi, abobora, alface, açaí, acerola, arroz, azeite de babaçu, banana, bacuri, batata doce, beijú de fécula, berinjela, biscoitos, buriti, coentros, couve, cajá, caju, carne bovina, carne suína, carne de frango caipira, carne ovina, doce, farinhas, feijão, polpas de frutas, manga, mamão, laranja, melancia, maxixe, melão, murici, milho verde, ovos, pão, peixe, pepino, pequi, pimenta, pimentão, quiabo, raiz de mandioca, rúcula, tomate, vinagreira.

Tabela 2. Farinhas comercializadas no PAA no munícipio de Bacuri, MA.

\begin{tabular}{lc}
\hline Descrição & Valor $(\mathrm{kg})$ \\
\hline Farinha de babaçu & 19,08 \\
Farinha de mesocarpo do babaçu & 19,08 \\
Farinha de mandioca d'agua & 5,15 \\
Farinha de mandioca seca fina & 5,20 \\
\hline
\end{tabular}

${ }^{1}$ Programa de Aquisição de Alimentos

Vale ressaltar que o programa não substitui os alimentos e sim complementa. No período de janeiro a agosto deste ano a comercialização dos agricultores do programa somou um total de $\mathrm{R} \$ 77.787,81$ (Tabela 3). Segundo relato dos agricultores, o programa tem contribuído para a valorização dos produtos que antes não eram valorizados na região, e também contribui para aquisição de bens e serviços trazendo 
maiores lucros e fazendo com que o agricultor permaneça na atividade. Segundo Camargo (2013) apesar das críticas é indiscutível afirmar que programas como o PAA permite o reconhecimento e o fortalecimento da agricultura familiar como produtora de alimentos e agente econômico plenamente integrado a outros setores da sociedade, além disto apresenta-se como mecanismo de inclusão e legitimação dos assentados da reforma agrária na vida social e econômica local.

Tabela 3. Valores relativos à comercialização mensal por agricultores $\mathrm{PAA}^{1}$ no município de Bacuri, Maranhão no período de janeiro a agosto de 2019

\begin{tabular}{lc}
\hline Meses & Total R\$ \\
\hline Janeiro & $9.990,53$ \\
Fevereiro & $9.967,12$ \\
Março & $10.551,25$ \\
Abril & $9.410,91$ \\
Maio & $8.830,10$ \\
Junho & $9.319,70$ \\
Julho & $10.737,00$ \\
Agosto & $8.981,20$ \\
\hline
\end{tabular}

${ }^{1}$ Programa de Aquisição de Alimentos

O PAA possui seis modalidades: Doação Simultânea; Compra Direta, Formação de Estoques, PAA Leite, Compra Institucional e Aquisição de Sementes (Veloso, 2017). Em Bacuri, MA a modalidade é a compra direta. Isto é realizado uma vez na semana, em que no mesmo dia que os produtores entregam o produto, a secretaria de agricultura familiar e meio ambiente faz a distribuição para as entidades, e o principal motivo disto é o fato da maioria dos alimentos serem perecíveis. Segundo Hespanhol (2013) o programa funciona de maneira a adquirir alimentos produzidos pelos agricultores familiares a preços baseados na cotação do mercado regional e fornecê-los às entidades da rede socioassistencial. Vale ressaltar que no município de Bacuri, o preço é estabelecido pela secretaria desde o início do programa e não a critério do agricultor.

Com relação a entrega dos produtos, conforme afirmam Camargo et al. (2013), a logística é um dos maiores gargalos enfrentados pelos agricultores, já que a maior parte das associações e cooperativas de produtores familiares não tem caminhão ou outro veículo para transportar sua produção, e terceirizar o frete diminui sua renda. Em Bacuri, a logística dos produtos dos produtores até a sede da secretaria no município é realizada por conta destes, pois nem a prefeitura ou associações se responsabilizam. O veículo utilizado depende da distância, pois os mesmos estão distribuídos entre os povoados. Dos veículos utilizados estão motos, carroças e carros fretados.

\section{Conclusão}

O Programa de Aquisição de Alimentos (PAA) no município de Bacuri, Maranhão tem contribuído de forma positiva para o município, para as entidades beneficiadas e principalmente para os agricultores bacurienses, e além de suprir quem recebe, diversifica as refeições com variedade de produtos comercializados e valorizados, com predominância da farinha que é referência de produção local.

\section{Agradecimentos}

Secretaria municipal de agricultura familiar e meio ambiente de Bacuri, MA.

\section{Referências}

BRASIL. (2006). Lei $n^{o}$ 11.326, de 24 de julho de 2006. Disponível em: http://www.planalto.gov.br/ccivil_03/_ato2004- 2006/2006/lei/111326.htm Acesso em: 20 de outubro de 2019.

BRASIL. (2010). Ministério do Desenvolvimento Agrário (MDA). Programa de Aquisição de Alimentos (PAA). Disponível em: http://www.mda.gov.br/portal/saf/programas/paa Acessado em 12 de Abril. 2012.

Camargo, R. A. L., Baccarin, J. G. \& Silva, D. B. P. 2013. O papel do Programa de aquisição de Alimentos (PAA) e do Programa Nacional de Alimentação Escolar (PNAE) no fortalecimento da 
agricultura familiar e promoção da segurança alimentar e nutricional. Temas de Administração Pública.

Chmielewska, D., Souza, D. \& Lourette, A. A. 2010. O Programa de Aquisição de Alimentos da Agricultura Familiar (PAA) e as práticas dos agricultores participantes orientadas ao mercado: estudo de caso no estado de Sergipe. Texto para Discussão 1510 - IPEA, Brasília.

Delgado, G. C., Conceição, J. C. \& Oliveira, J. J. 2005. Relatório de avaliação do Programa de Aquisição de Alimentos da agricultura familiar (PAA). IPEA, Texto n 1145, Brasília, dez/2005. Disponível em: http://www.ipea.gov.br/pub/td_1145.pdf. Acesso em 10 de abril, 2020.

Grisa, C. 2012. Políticas públicas para a agricultura familiar no Brasil: produção e institucionalização das ideias. Tese de doutorado, Rio de Janeiro, UFRJ, $285 \mathrm{f}$.

Hespanhol, R. A. M. 2013. Programa de Aquisição de Alimentos: limites e potencialidades de políticas de segurança alimentar para a agricultura familiar. Sociedade \& Natureza, 25, 469-483. DOI: https://doi.org/10.1590/s1982-45132013000300003

IBGE. (2019). População estimada. Diretoria de Pesquisas, Coordenação de População e Indicadores Sociais, Estimativas da população residente com data de referência 1o de julho.

Siliprandi, E. \& Cintrão, R. 2011. As mulheres agricultoras no Programa de Aquisição de Alimentos (PAA). Segurança Alimentar e Nutricional, 18: 12-32. DOI: https://doi.org/10.20396/san.v18i2.8634675

Veloso, F. 2017. A importância do Programa de Aquisição de Alimentos para as famílias e entidades beneficiárias na região da nova alta paulista. Revista da Geografia do Trabalho, 8: 147-176. DOI: https://doi.org/10.33026/peg.v18i2.5166

\section{Histórico do artigo:}

Recebido: 12 de novembro de 2020. Aprovado: 10 de dezembro de 2020 . Disponível online: 8 de março de 2021 .
Licenciamento: Este artigo é publicado na modalidade Acesso Aberto sob a licença Creative Commons Atribuição 4.0 (CC-BY 4.0), a qual permite uso irrestrito, distribuição, reprodução em qualquer meio, desde que o autor e a fonte sejam devidamente creditados. 